\title{
Change in the Diagnosis of Appendicitis by Using a Computed Tomography Scan and the Necessity for a New Scoring System to Determine the Severity of the Appendicitis
}

\author{
Byung Wook Min \\ Division of Colorectal Surgery, Department of Surgery, Korea University College of Medicine, Seoul, Korea
}

See Article on Page 192-197

Acute appendicitis is the most common indication for surgery in patients admitted to hospital due to an acute abdomen. Although most are uncomplicated, about $20 \%$ of all acute appendicitis cases are complicated, leading to local or diffuse peritonitis. An urgent appendectomy is the recommended treatment for both complicated and uncomplicated appendicitis. The appendectomy, which has been the first choice for the treatment of acute appendicitis for over 120 years, is a classic surgical procedure [1]. Nowadays, a laparoscopic appendectomy is widely practiced for its benefits, such as significantly shorter operative time, lower incidence of wound infection, and reduced length of hospital stay [2].

Although an appendectomy is generally well tolerated, it is still considered a major surgical intervention and can be associated with postoperative morbidity in about $2 \%-23 \%$ of patients [3]. According to a study that followed patients for over a decade, 3\% of the patients undergoing appendectomy were readmitted for intestinal obstruction related to postoperative adhesion $[4,5]$. Therefore, physicians are taking higher interest in noninvasive interventions, such as antibiotic therapy, as a primary treatment. Although the appendectomy remains the standard approach for treating appendicitis [6], several studies have already suggested that appendicitis can be treated with antibiotics [5].

Correspondence to: Byung Wook Min, M.D.

Division of Colorectal Surgery, Department of Surgery, Korea University Guro Hospital, Korea University College of Medicine, 148 Gurodong-ro, Guro-gu, Seoul 08308, Korea

Tel: +82-2-2626-3079, Fax: +82-2-2626-1148

E-mail:gsmin@korea.ac.kr

(C) 2015 The Korean Society of Coloproctology

This is an open-access article distributed under the terms of the Creative Commons Attribution NonCommercial License (http://creativecommons.org/licenses/by-nc/3.0) which permits unrestricted noncommercial use, distribution, and reproduction in any medium, provided the original work is properly cited.
Two well-studied appendicitis scoring systems based on clinical symptoms were used to diagnose appendicitis: the Alfredo Alvarado system for adults and the Madan Samuel system for children. The Alvarado score was developed in Philadelphia in the mid-1980s and has a sensitivity of $81 \%$ and a specificity of $74 \%$ [7]. The Pediatric Appendicitis Score was developed to diagnose appendicitis in children and has a high sensitivity of $100 \%$ and specificity of $92 \%$ [8]. Although these scoring systems were widely used to diagnose appendicitis in the past, they are no longer practically implicated. Recently, various diagnostic tools, such as computed tomography (CT) and ultrasound, have been developed to diagnose appendicitis. With the improvement of such radiologic tools, determining the severity of and diagnosing appendicitis have become more accurate.

The development of radiologic tools has provided many advantages for diagnosing appendicitis and determining its severity. The increased use of CT has reduced the rate of negative (unnecessary) appendectomies [9]. A meta-analysis consisting of data from 31 studies revealed that both the sensitivity and the specificity of CT for appendicitis were as high as 94\% [10]. The development of a precise scoring system based on CT to distinguish between complicated and uncomplicated appendicitis has led to an improvement in diagnostic accuracy [11]. This system provides the physician with the evidence needed to decide on a treatment strategy for appendicitis patients.

A meta-analysis [12] of randomized controlled trials comparing antibiotics with appendectomies has shown that although antibiotic treatment alone can be successful in $77 \%-95 \%$ of the cases, patients should be made aware of the fact that the failure rate during the first year, with a need for readmission or surgery, is around $25 \%-30 \%$. However, recently conducted research proposed the use of antibiotics as the single treatment for uncomplicated appendicitis. However, one should note that more accurate selection criteria, based on combinations of clinical risk scores and imaging, are required for patients or subgroups of patients in whom 
primary antibiotic treatment is more likely to succeed in the longterm, and CT could be of assistance in the process of selecting patients suitable for antibiotics therapy. Although the appendectomy is the best treatment for the appendicitis, studies on the use of antibiotics therapy to treat patients with uncomplicated appendicitis are still meaningful; thus, efforts for such research should be supported.

\section{CONFLICT OF INTEREST}

No potential conflict of interest relevant to this article was reported.

\section{REFERENCES}

1. Harris CW. Abraham GROVES of Fergus: the first elective appendectomy? Can J Surg 1961;4:405-10.

2. Ikeda H, Ishimaru Y, Takayasu H, Okamura K, Kisaki Y, Fujino J. Laparoscopic versus open appendectomy in children with uncomplicated and complicated appendicitis. J Pediatr Surg 2004;39: 1680-5.

3. Konstantinidis KM, Anastasakou KA, Vorias MN, Sambalis GH, Georgiou MK, Xiarchos AG. A decade of laparoscopic appendectomy: presentation of 1,026 patients with suspected appendicitis treated in a single surgical department. J Laparoendosc Adv Surg Tech A 2008;18:248-58.

4. Parker MC, Ellis H, Moran BJ, Thompson JN, Wilson MS, Menzies D, et al. Postoperative adhesions: ten-year follow-up of 12,584 patients undergoing lower abdominal surgery. Dis Colon Rectum 2001;44:822-9.

5. Hansson J, Korner U, Khorram-Manesh A, Solberg A, Lundholm K. Randomized clinical trial of antibiotic therapy versus appendicectomy as primary treatment of acute appendicitis in unselected patients. Br J Surg 2009;96:473-81.

6. Salminen P, Paajanen H, Rautio T, Nordström P, Aarnio M, Rantanen T, et al. Antibiotic therapy vs appendectomy for treatment of uncomplicated acute appendicitis: the APPAC randomized clinical trial. JAMA 2015;313:2340-8.

7. Alvarado A. A practical score for the early diagnosis of acute appendicitis. Ann Emerg Med 1986;15:557-64.

8. Samuel M. Pediatric appendicitis score. J Pediatr Surg 2002;37: 877-81.

9. Raman SS, Osuagwu FC, Kadell B, Cryer H, Sayre J, Lu DS. Effect of CT on false positive diagnosis of appendicitis and perforation. N Engl J Med 2008;358:972-3.

10. Doria AS, Moineddin R, Kellenberger CJ, Epelman M, Beyene J, Schuh S, et al. US or CT for diagnosis of appendicitis in children and adults? A meta-analysis. Radiology 2006;241:83-94.

11. Kim TH, Cho BS, Jung JH, Lee MS, Jang JH, Kim CN. Predictive factors to distinguish between patients with noncomplicated appendicitis and those with complicated appendicitis. Ann Coloproctol 2015;31:192-7.

12. Varadhan KK, Neal KR, Lobo DN. Safety and efficacy of antibiotics compared with appendicectomy for treatment of uncomplicated acute appendicitis: meta-analysis of randomised controlled trials. BMJ 2012;344:e2156. 